\title{
Malakoplakia of the Urinary Bladder in a Patient with Chronic Lymphocytic Leukemia Under Ibrutinib Therapy: A Case Report
}

\author{
SOTIRIOS SACHANAS ${ }^{1}$, GERASSIMOS A. PANGALIS ${ }^{1}$, PETROS KAROUZAKIS ${ }^{2}$, \\ EFSTATHIOS KOULIERIS ${ }^{1}$, MARIA MOSCHOGIANNIS ${ }^{1}$, CHRISTINA KALPADAKIS $^{3}$, \\ XANTHI YIAKOUMIS ${ }^{1}$ and DIMITRA RONTOGIANNI ${ }^{4}$ \\ ${ }^{1}$ Department of Haematology, Athens Medical Center-Psychikon Branch, Athens, Greece; \\ ${ }^{2}$ Athens Medical Center-Psychikon Branch, Athens, Greece; \\ ${ }^{3}$ Department of Haematology, Heraklion University Hospital, University of Crete, Heraklion, Greece; \\ ${ }^{4}$ Department of Anatomic Pathology, Evangelismos General Hospital, Athens, Greece
}

\begin{abstract}
Malakoplakia, a rare granulomatous disease of infectious etiology, is commonly observed in immunocompromised patients. Chronic lymphocytic leukemia (CLL) is characterized by profound immune dysregulation resulting in significant infection-related morbidity and mortality, and several drugs used in CLL treatment have a severe immunosuppressive effect. Ibrutinib, has become a new standard-of-care in patients with CLL, especially for those harboring unfavorable genetic characteristics such as $17 p$ deletion, with however, unknown long-term immunological consequences. Here we report a case of a patient with CLL with $17 p$ deletion diagnosed with malakoplakia of the urinary bladder under ibrutinib therapy who developed severe hypogammaglobulinemia during treatment administration. Presumably, ibrutinib might contribute to the development of malakoplakia on the grounds of induced immunosuppression. This case report highlights the need for regular assessment of immunogammaglobulin adequacy during treatment with ibrutinib, considering that it should be given on a permanent basis.
\end{abstract}

Malakoplakia is a rare granulomatous disease of infectious etiology. The most common site of involvement of malakoplakia is the urinary tract, followed by the gastrointestinal tract. It is characterized by aggregates of histiocytes with abundant eosinophilic cytoplasm known as

Correspondence to: Dr. Sotirios Sachanas, Department of Haematology, Athens Medical Center-Psychikon Branch, Andersen 1, N. Psychikon 11525, Athens, Greece. E-mail: ssachanas@gmail.com

Key Words: Malakoplakia, urinary bladder, chronic lymphocytic leukemia, ibrutinib, hypogammaglobulinemia.
Hansemann cells, intermingled with lymphocytes, plasma cells and neutrophils. Malakoplakia is believed to result from the inadequate killing of bacteria by macrophages or monocytes with defective phagolysosomal activity. Partially digested bacteria accumulate in monocytes or macrophages and result in the deposition of calcium and iron on residual bacterial glycolipid, consisting the so-called MichaelisGutmann body, which is considered pathognomonic for malakoplakia. This specific disorder is commonly observed to occur in immunocompromised patients and it is possible that its rarity is associated with the level of immunosuppression required (1-3). On the other hand, hematological malignancies are frequently associated with serious impairment of the immune system; among these chronic lymphocytic leukemia (CLL) is characterized, in some cases, by profound immune dysregulation and hypogammaglobulinemia, which contributes to the increased rate of infection of patients with CLL (4-6). Moreover, several drugs used in the treatment of CLL have a severe immunosuppressive effect.

Ibrutinib, an orally administered inhibitor of bruton tyrosine kinase (BTK) that antagonizes b-cell receptor (BCR) has become a new standard-of-care in CLL, especially for patients harboring unfavorable genetic characteristics such as $17 \mathrm{p}$ deletion $(7,8)$. Although the short-term toxicity of ibrutinib is manageable, there is inadequate information regarding the long-term toxicity as the follow-up of patients included in trials is quite short.

Here we report a case of a patient with CLL with $17 \mathrm{p}$ deletion who was diagnosed with malakoplakia of the urinary bladder while she was receiving therapy with ibrutinib, presented with severe hypogammaglobulinaemia and we discuss the possible immunosuppressive effect of this agent. 


\section{Case Report}

A 69-year-old female was diagnosed with CLL in 2011, clinical stage A according to the Binet staging system. At her presentation, she was clinically fit and there was no palpable lymphadenopathy present. Her blood cell counts showed: white blood cell (WBC): $8.78 \times 10^{9} / 1$, lymphocytes: $5.56 \times 10^{9} / 1$, granulocytes: $2.59 \times 10^{9} / 1$, hemoglobulin $(\mathrm{Hb})$ : $13 \mathrm{~g} / \mathrm{dl}$, hematocrit $(\mathrm{Ht}): 39.1 \%$, platelets: $220 \times 10^{9} / 1$. Biochemical examination did not reveal any abnormal findings and serum electrophoresis disclosed that the immunogammaglobulin level was $0.95 \mathrm{~g} / \mathrm{dl}$ (normal range $=0.7-1.6 \mathrm{~g} / \mathrm{dl})$. Blood smear examination disclosed a prominent population of small-sized, mature lymphocytes, as well as the presence of nuclear shadows, and blood immunophenotypic analysis was consistent with CLL. Bone marrow examination revealed infiltration by CLL cells at a percentage of $20 \%$.

The patient was placed on a watch-and-wait policy for 2 years. During follow-up, she underwent regularly blood examinations which showed only a slight increase in the absolute lymphocyte count. As far as the immunogammaglobulin levels were concerned, a random assessment in 2012 gave the following values: IgG: $573 \mathrm{mg} / \mathrm{dl}$ (normal range $=650$ $1,600 \mathrm{mg} / \mathrm{dl}$ ), IgM: $112.3 \mathrm{mg} / \mathrm{dl}$ (normal range=50.0-300.0 $\mathrm{mg} / \mathrm{dl}$ ), IgA: $100.4 \mathrm{mg} / \mathrm{dl}$ (normal range $=40.0-350.0 \mathrm{mg} / \mathrm{dl}$ ).

In February 2013, our patient presented with enlarged cervical, axillary and inguinal lymph nodes. Computed tomographic evaluation also disclosed enlarged abdominal lymph nodes, as well as the presence of slight splenomegaly. Examination of the peripheral blood revealed that the white blood cell count was $59 \times 10^{9} / 1$, with $86 \%$ of lymphocytes, $\mathrm{Hb}$ : $11.8 \mathrm{~g} / \mathrm{dl}, \mathrm{Ht}: 39.1 \%$, platelets: $97 \times 10^{9} / 1, \mathrm{IgG}: 612 \mathrm{mg} / \mathrm{dl}$, IgM: $101 \mathrm{mg} / \mathrm{dl}$, and $\mathrm{IgA}: 61 \mathrm{mg} / \mathrm{dl}$; bone marrow biopsy revealed an infiltration of $70 \%$ by CLL cells. Furthermore, a biopsy of a cervical lymph node was performed which disclosed an infiltration by small-sized lymphocytes with immunohistochemical features consistent with CLL, mixed with an increased number of paraimmunoblasts.

Before treatment initiation, fluorescence in situ hybridization analysis for $17 \mathrm{p}$ del was performed, which disclosed that the patient harbored deletion of $17 \mathrm{p}$. In conclusion, the patient was classified in the high-risk CLL group and was in need of firstline treatment. Thus, the patient was administered the ofatumumab regimen, receiving the initial standard weekly protocol and subsequently the first monthly infusion, however, without any significant response. Thereafter, she was placed on second-line therapy with combination of rituximab and bendamustine, but experienced stable disease after four cycles of the aforementioned regimen. At that time period, it was feasible to have access to the new BCR inhibitor, ibrutinib, and thus, she received this agent in November 2014 at the standard dose $(420 \mathrm{mg} /$ daily). Gradually, the enlarged lymph nodes disappeared and after a transient increase of peripheral lymphocytes, eventually there was a restoration of normal blood cell counts. Twelve months after ibrutinib initiation, our patient presented to our Department with hematuria, while her disease was still in remission. Computerized tomography of the abdomen and the pelvis revealed the presence of a mass of $5 \times 3 \times 2 \mathrm{~cm}$ covering the anterior side wall of the urinary bladder, while there were no enlarged abdominal lymph nodes (Figure 1). Urinary analysis showed hematuria and the urinary culture was positive for Escherichia coli. At that time point, estimation of serum immunogammaglobulin levels was as follows: IgG: $75 \mathrm{mg} / \mathrm{dl}$, IgM: $49.1 \mathrm{mg} / \mathrm{dl}$, and IgA: $30.9 \mathrm{mg} / \mathrm{dl}$.

Transurethal biopsy of the bladder was performed and revealed sheets of histiocytes with fine eosinophilic cytoplasmic granules and basophilic inclusions positively stained with von Kossa stain (Michaelis-Gutmann bodies), while there was no infiltration by malignant cells (Figure 2). The above findings were consistent with the diagnosis of malakoplakia of the urinary bladder. After this diagnosis, the patient was placed on antibiotics while she received intravenous immunoglobulin replacement. She is currently under therapy without hematuria and is about to undergo reevaluation of the urinary bladder mass.

\section{Discussion}

The established treatment algorithms for CLL are currently challenged by the advent of novel drugs whose mechanisms of action are different from those of conventional cytotoxic agents and antibodies (9). One of the most promising new agents is ibrutinib, which is an orally administered inhibitor of BTK that antagonizes BCR, which is critical in normal Blymphopoiesis (7-8). It has been reported that germline inactivating mutations in BTK lead into an immunodeficiency syndrome first described by Bruton in boys suffering from recurrent bacterial infections. These boys proved to have a severe defect in B-cell maturation, resulting in the virtual absence of immunoglobulin (10-12). On the other hand, it is well known that CLL is characterized by profound immune dysregulation. Hypogammaglobulinemia is present in a varying percentage of patients with B-CLL at the time of diagnosis, depending on the defined lower normal limit, and it is correlated with Binet stage (4).

Patients with heavy bone marrow infiltration or absolute lymphocyte counts exceeding $40 \times 10^{9} / 1$ tend to be hypogammaglobulinemic at diagnosis (4). In relation to immunoglobulin subclasses, it has been noted that low levels of $\operatorname{IgA}, \operatorname{IgM}$ and $\operatorname{IgG}$ occur in $30 \%, 30 \%$ and $10 \%$, respectively, of patients with B-CLL at the time of diagnosis (4). Despite its low frequency at the time of diagnosis, the appearance of hypogammaglobulinemia seems to be a continuous phenomenon during the clinical course of untreated B-CLL, affecting up to $75 \%$ of patients. IgA and IgM levels 

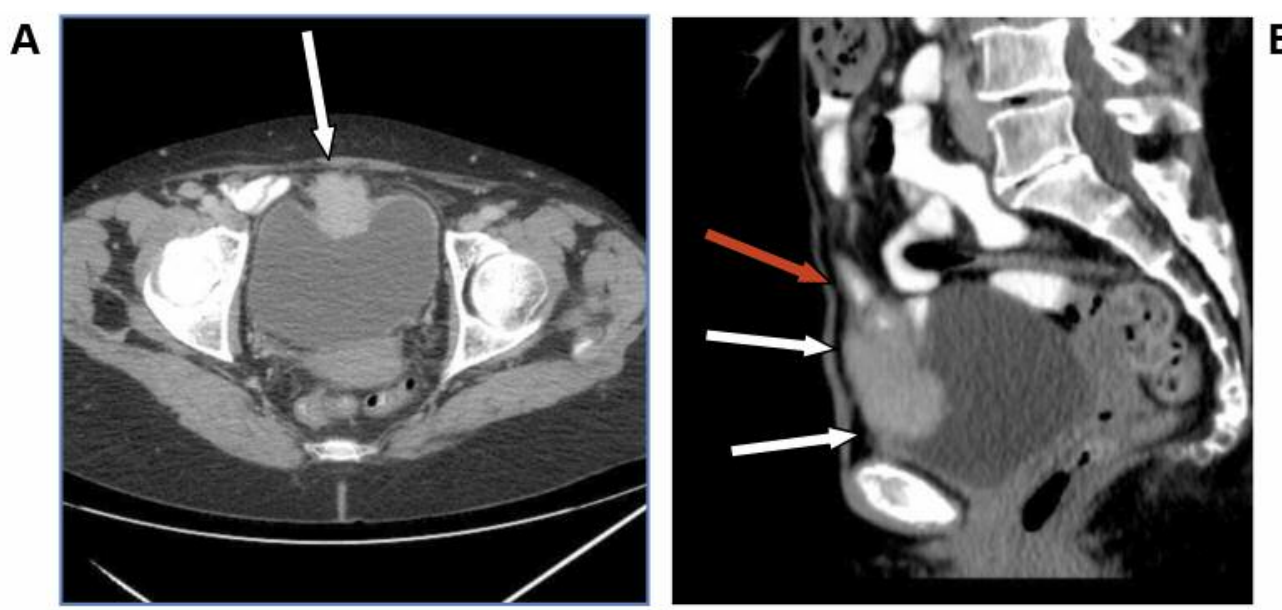

Figure 1. Computerized tomography of the urinary bladder tumor. A: Transverse section: Presence of a mass located at the anterior wall of urinary bladder which is infiltrated (white arrows). B: Sagittal view of the tumor (white arrows). Apart from the urinary bladder, the ileum is also infiltrated (red arrow).
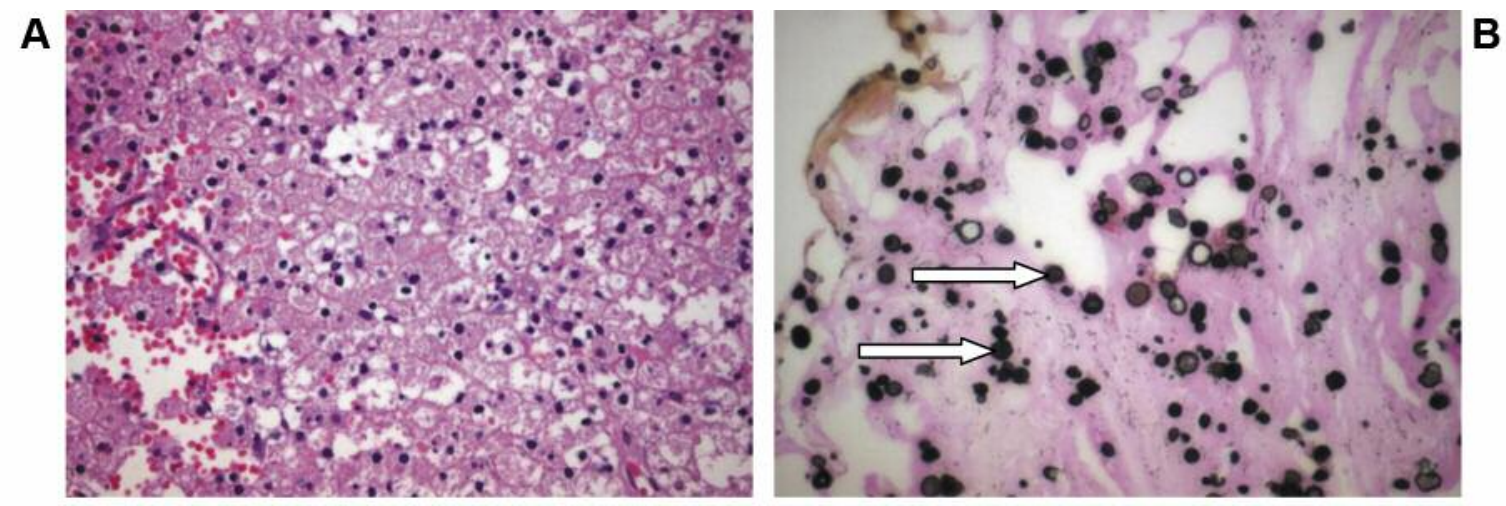

Figure 2. Histology of the urinary bladder tumor. A: Hematoxylin and eosin stain reveals the presence of abundant histiocytes. Original magnification, ×40. B: Michaelis-Gutmann bodies (white arrows) are present (von Kossa stain). Original magnification, $\times 60$.

are more frequently reduced than $\mathrm{IgG}$, while chemotherapy usually does not improve hypogammaglo-bulinemia, even in patients who enter complete clinical remission (4).

To what extend ibrutinib-induced BTK inhibition affects normal B-cell function and immunoglobulin levels is not yet fully known. There are some clinical studies in which the immunoglobulin levels were monitored during treatment, showing a gradual improvement of IgA level but also a decline in IgG level. The latter change was apparent after a prolonged period $(8,13-14)$.

In our case, the patient presented with almost normal $\operatorname{IgG}$ levels while IgA and IgM levels were within normal limits before the initiation of ibrutinib treatment. In fact, sequential assessment of immunoglobulin levels was not performed during ibrutinib treatment in order to monitor the possible changes concerning the quantity of each immunoglobulin separately. However, the estimation of immunoglobulin levels performed at the time of the detection of the bladder mass revealed severe hypogammaglobulinemia and, impressively, an extreme decline of $\mathrm{IgG}$ level to $75 \mathrm{mg} / \mathrm{dl}$. Of importance was the fact that at the time of the diagnosis of malakoplakia, CLL was in remission with normalization of blood cell counts and no enlarged abdominal lymph nodes, as documented.

Although hypogammaglobulinemia is a common finding during the course of disease, the decrease of immunoglobulin levels, focusing mainly on the depth of decline of IgG level observed after ibrutinib administration, raises the question of the possible involvement of ibrutinib treatment, bearing in mind that the long-term immunological consequences of pharmacological BTK inhibition are unknown. 
To our knowledge, this is a first case of malakoplakia of the urinary tract in a patient with CLL under therapy with novel agents such as ibrutinib and this highlights the need for regular assessment of immunogammaglobulin adequacy during treatment with these agents, considering that they should be given on a permanent basis.

\section{Conflicts of Interest}

None.

\section{References}

1 Stanton MJ and Maxted W: Malacoplakia: a study of the literature and current concepts of pathogenesis, diagnosis and treatment. J Urol 125: 139-146, 1981.

2 Wielenberg AJ, Demos TC, Rangachari B and Turk T: Malakoplakia presenting as a solitary renal mass. Am J Roentgenol 183: 1703-1705, 2004.

3 Ayllon J, Verkarre V, Scotté F, Fournier L, Corréas JM, Mejean A, Teghom C and Oudard S: Renal malacoplakia: Case report of a differential diagnosis for renal cell carcinoma. Am J Case Rep 13: 38-40, 2012.

4 Pangalis GA, Vassilakopoulos TP, Dimopoulou MN, Siakantaris MP Kontopidou FN and Angelopoulou MK: B-Chronic lymphocytic leukemia: practical aspects. Hematol Oncol 20: 103-146, 2002.

5 Morrison VA: Infectious complications in patients with chronic lymphocytic leukemia: pathogenesis, spectrum of infection, and approaches to prophylaxis. Clin Lymphoma Myeloma 9: 365370, 2009.

6 Hamblin $\mathrm{AD}$ and Hamblin TJ: The immunodeficiency of chronic lymphocytic leukaemia. Br Med Bull 87: 49-62, 2008.

7 Byrd JC, Furman RR, Coutre SE, Burger JA, Blum KA, Coleman M, Wierda WG, Jones JA, Zhao W, Heerema NA, Johnson AJ, Shaw Y, Bilotti E, Zhou C, James DF and O'Brien $\mathrm{S}$ : Three-year follow-up of treatment-naive and previously treated patients with CLL and SLL receiving single-agent ibrutinib. Blood 125: 2497-2506, 2015.
8 Byrd JC, Furman RR, Coutre SE, Flinn IW, Burger JA, Blum KA, Grant B, Sharman JP, Coleman M, Wierda WG, Jones JA, Zhao W, Heerema NA, Johnson AJ, Sukbuntherng J, Chang BY, Clow F, Hedrick E, Buggy JJ, James DF and O'Brien S: Targeting BTK with ibrutinib in relapsed chronic lymphocytic leukemia. N Engl J Med 369: 32-42, 2013.

9 Dreger P, Schetelig J, Andersen N, Corradini P, van Gelder M, Gribben J, Kimby E, Michallet M, Moreno C, Stilgenbauer S and Montserrat E: Managing high-risk CLL during transition to a new treatment era: Stem cell transplantation or novel agents? European Research Initiative on CLL (ERIC) and the European Society for Blood and Marrow Transplantation (EBMT). Blood 124: 3841-3849, 2014.

10 Bruton OC: Agammaglobulinemia. Pediatrics 9: 722-728, 1952.

11 Rawlings DJ, Saffran DC, Tsukada S, Largaespada DA, Grimaldi JC, Cohen L, Mohr RN, Bazan JF, Howard M and Copeland NG: Mutation of unique region of Bruton's tyrosine kinase in immunodeficient XID mice. Science 261: 358-336, 1993.

12 Satterthwaite AB and Witte ON: The role of Bruton's tyrosine kinase in B-cell development and function: a genetic perspective. Immunol Rev 175: 120-127, 2000.

13 Sun C, Tian X, Lee YS, Gunti S, Lipsky A, Herman SE, Salem D, Stetler-Stevenson M, Yuan C, Kardava L, Moir S, Maric I, Valdez J, Soto S, Marti GE, Farooqui MZ, Notkins AL, Wiestner A and Aue G: Partial reconstitution of humoral immunity and fewer infections in patients with chronic lymphocytic leukemia treated with ibrutinib. Blood 126: 2213-2219, 2015.

14 O'Brien S, Furman RR, Coutre SE, Sharman JP, Burger JA, Blum KA, Grant B, Richards DA, Coleman M, Wierda WG, Jones JA, Zhao W, Heerema NA, Johnson AJ, Izumi R, Hamdy A, Chang BY, Graef T, Clow F, Buggy JJ, James DF and Byrd JC: Ibrutinib as initial therapy for elderly patients with chronic lymphocytic leukaemia or small lymphocytic lymphoma: an open-label, multicentre, phase 1b/2 trial: Lancet Oncol 15: 4858,2014 .

Received June 23, 2016

Revised July 10, 2016

Accepted July 11, 2016 